\title{
Dilemas organizativos y narrativa partidaria: Acción Nacional en 2015
}

\section{Organizational dilemmas and the attempt to construct a new narrative: the Partido Acción Nacional in 2015}

\author{
Victor Reynoso* \\ Universidad de las Américas, Puebla, México \\ DoI: http://dx.doi.org/10.28928/revistaiztapalapa/812016/atc3/reynosov
}

\begin{abstract}
Resumen
El presente artículo hace un análisis del intento del Partido Acción Nacional (PAN) por construir una nueva narrativa a mediados del sexenio de Enrique Peña Nieto. Se parte de una caracterización del pan a partir de la teoría de articulación de fines e incentivos, y de la situación que vivió después de la derrota en la elección presidencial de 20I2. Dicha derrota y sus consecuencias es el contexto del análisis presentado. Se consideran también los conflictos internos, el desempeño en elecciones locales y federales y la renovación de la dirigencia nacional en una elección abierta a toda la militancia. El análisis se centra en el notable intento de construir una nueva narrativa en torno al combate a la corrupción. En la elección interna triunfó Ricardo Anaya, principal impulsor de la nueva narrativa, sobre Javier Corral.

Palabras clave: partidos políticos mexicanos, Acción Nacional, corrupción, narrativa partidaria, elecciones 2015 .
\end{abstract}

\section{Abstract}

This article is an analysis of the attempt of the Partido Acción Nacional to construct a new narrative in the middle of the six-year period of Enrique Peña Nieto. It is a characterization of the party from the theory of

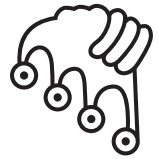

\section{IZTAPALAPA}

Agua sobre lajas
* Universidad de las Américas Puebla victorm.reynoso@udlap.mx 
articulation of goals and incentives and the situation that it lived after the defeat in the presidential election of 2012. This defeat and its consequences is the context of the analysis presented. The internal conflicts, the performance in local and federal elections and the renewal of the national leadership in an election open to all militancy are also analyzed. The analysis focuses on the remarkable attempt to construct a new narrative around the fight against corruption. In the internal election triumphed Ricardo Anaya, driving the new narrative, on Javier Corral.

Key words: Mexican Political Parties, Accion Nacional, corruption, 2015 elections. 
$A$ mediados del sexenio de Enrique Peña Nieto, y poco después de cumplir 75 años de su fundación, el PAN enfrentaba un problema serio de legitimidad, tanto interna como externa. No solo la derrota electoral de 20I2, cuando la candidata de este partido obtuvo el tercer lugar, sino sobre todo el desempeño panista en 12 años de gobiernos, que estuvo lejos de las expectativas que el propio partido tenía. Aunque se mantuvo la estabilidad macroeconómica y macropolítica (prácticamente todas las elecciones locales y nacionales se siguieron realizando y fueron la única fuente legítima para acceder a cargos de elección), en esos I2 años no cambiaron gran cosa los problemas que habían estado en el centro de la agenda política panista, como la corrupción, la impunidad o la ineficiencia gubernamental. En algunos casos se agravaron, o al menos se hicieron más visibles.

El asunto fue claro para los propios panistas. Después de los resultados negativos de la elección federal de 2009 formaron una "Comisión de reflexión" para analizar la derrota. Tras lo ocurrido en 2012 se formó otra comisión para lo mismo: de "Evaluación y mejora". Los diversos ejercicios de este tipo llevaron a los propios panistas a concluir que sus padecimientos como organización estaban "sobrediagnosticados". Exceso de diagnósticos, falta de tratamientos adecuados.

En agosto de 2015 Ricardo Anaya fue electo vigésimo presidente nacional del Partido Acción Nacional. La peculiar circunstancia de esta elección dio lugar al intento de una nueva narrativa panista, consecuencia del resultado electoral de 2012 y del balance de los dos sexenios en el poder presidencial. Este artículo analiza ese intento situándolo en el contexto en el que surge.

El análisis comienza con una revisión teórica enfocada a explicar el sentido de los cambios que está viviendo el pan a partir de los dilemas que enfrenta. Este partido parece ser un caso claro de articulación de fines y de incentivos: surgió como un "modelo racional" con objetivos externos a la organización, pero a mediados de la segunda década del siglo xxi presentaba claramente rasgos de un "modelo natural" cuyo objetivo central era la supervivencia del partido.

Después se analizan los conflictos internos vinculados a la problemática señalada. Al inicio de año, el expresidente de la República y del partido, Felipe Calderón 
Hinojosa, amenazó con dejarlo y formar otro, en una declaración que no tenía precedentes y que expresaba el nivel del conflicto interno. Mostraba también el problema de un partido que había abandonado, en alguna medida, sus objetivos originales para sustituirlos por el acceso al poder y la supervivencia de la organización.

Como parte fundamental del contexto o circunstancia en que se da la nueva narrativa se revisan también los resultados electorales de ese año. Aunque el partido mantuvo el mismo número de gubernaturas, dos, en los nueve estados que tuvieron elección disminuyó el número de diputados, tanto federales como locales.

Después de esa revisión se pasa al núcleo del artículo: el intento de una nueva narrativa. La dirigencia partidaria, concretamente Ricardo Anaya, primero como presidente interino y luego como presidente electo, puso en el centro del discurso panista el combate a la corrupción, dentro y fuera del PAN.

Hubo un cambio importante: si bien al principio del año la red de relaciones en torno a Calderón parecía estar marginada de la dirección del partido, marginación que se expresó en que su esposa Margarita Zavala no pudiera ser candidata a diputada federal, hacia finales de año hubo un acercamiento de Calderón y Zavala con el nuevo presidente del partido, Ricardo Anaya. Paralelo a este acercamiento se dio el fin del "maderismo", de la red que estableció Gustavo Madero Muñoz durante su dirigencia. Este cambio en las redes y los grupos que dirigen el PAN está vinculado a un nuevo tipo de narrativa centrado en la denuncia de la corrupción. Está por verse si habrá alguna modificación al respecto en las prácticas de los dirigentes y los gobiernos panistas. Por lo pronto es claro que hay un cambio en el discurso.

\section{El PAN hacia 20I5ः la articulación de los fines}

Pocos partidos se adecuan tan bien al esquema teórico de Ángelo Panebianco (1985) como Acción Nacional. Al menos en un aspecto concreto: la articulación de fines. Como en toda organización, en un partido político sus integrantes persiguen una gran diversidad de objetivos. Pero algunos predominan y le dan el tono a la organización. Desde Michels se ha planteado que en algunos casos los partidos nacen para buscar un fin externo a ellos, una "causa" o un "propósito" (el socialismo, en los partidos analizados por Michels). Pero tarde o temprano abandonan ese afán y se concentran en la supervivencia de la organización. 
El planteamiento anterior es conocido como la teoría de la sustitución de los fines (Panebianco, 1985: 38). ${ }^{1}$ Está estrechamente vinculado a otro dilema organizativo que enfrentan los partidos políticos: incentivos colectivos e incentivos selectivos. Los primeros son los que reciben por igual todos los miembros de la organización y coinciden, a grandes rasgos, con los primeros fines: la causa o el propósito del partido en su fundación, en su modelo originario. Los incentivos selectivos, como el término lo indica, se concentran en algunos miembros de la organización: cargos de dirigentes dentro del partido, de funcionarios públicos o de representantes de elección popular (Panebianco, 1985: 39-43).

La teoría de la sustitución de fines plantea, pues, que los partidos políticos suelen iniciar centrados en una causa, fin u objetivo externo a ellos, lo que Wilson (1995: 9) llama incentivos de propósito. Pero con el tiempo lo sustituyen por un interés particular: que la organización sobreviva, pues es fuente de empleos e ingresos para sus integrantes. Eso que equivale a decir que los incentivos colectivos que originalmente predominaban en la organización tienden a ser sustituidos por incentivos selectivos: cargos públicos, sueldos y salarios, oportunidades de negocios, etc., sustituyen al incentivo original, la causa.

Pero Panebianco (1985: 5 I y ss.) introduce una corrección fundamental: los fines y los incentivos, más que sustituirse, se articulan. Un partido moderno requiere ambos: una causa que legitime interna y externamente a la organización y un conjunto de incentivos selectivos o materiales que motiven y sustenten la participación de sus dirigentes.

Quizá ningún partido político mexicano siga este esquema con la misma claridad que Acción Nacional. Cuando se funda el Partido Nacional Revolucionario, en I929, ese partido tenía prácticamente el monopolio de los incentivos selectivos partidarios. ${ }^{2}$ El Partido de la Revolución Democrática, en 1989, se centraba ciertamente en una causa, pero nació ya con cuatro senadores, varias decenas de diputados federales y la posibilidad real de acceder a más cargos públicos, a más incentivos selectivos.

1 En el mismo libro de Panebianco (1985) pueden verse los conceptos de "modelo racional" y "modelo natural" tomados de la teoría de las organizaciones, que plantean de manera más completa la cuestión de la sustitución de fines.

2 El tema ha sido muy tratado, pero para un análisis reciente véase Hernández Rodríguez (2016: 19): "Los partidos nacen para ejercer el poder, pero no todos nacen para luchar por él y eventualmente conseguirlo. El Partido Revolucionario Institucional, en su primera versión, no tuvo como propósito alcanzar el poder sino retenerlo". Quizá a "retenerlo" habría que añadir "administrarlo, repartirlo, arbitrarlo". 
El pan tuvo sus primeros diputados federales casi siete años después de fundado. Y su acceso a los cargos públicos fue mínimo, improbable e inestable en las primeras décadas. Estaba centrado en su causa. La situación cambiaría radicalmente con la transición mexicana. Además de dos presidencias de la República (2000-2006 y 2006-2012), con todos los beneficios materiales que implican para dirigentes y militantes panistas, ha tenido acceso a un buen número de gubernaturas, ayuntamientos, diputaciones y senadurías.

¿Se articularon los fines y los incentivos panistas, o se sustituyeron? En este dilema está inscrito, en lo que va del presente siglo, el Partido Acción Nacional. No es casual que sea el tema, con otros términos, del libro de Luis Felipe Bravo Mena, militante panista desde 1969 y que entre otros cargos ha sido presidente nacional de su partido de 1999 a 2005. Su tesis central se fundamenta en la distinción entre el panismo como cultura política y el PAN como organización, y sostiene que aunque la organización llamada PAN sobreviva, la cultura política que le dio origen puede desaparecer (Bravo Mena 20I4: II). Es decir, la organización y el entramado de intereses que representa (presupuestos, cargos públicos, acceso a diversas oportunidades, etc.) como fin sustituirá los fines, causas y propósitos originarios del partido. Este es el dilema panista de principios del siglo xxI. Esta es la cuestión que pretende investigar este artículo, centrándose en el intento de una nueva narrativa a mediados de la segunda década del siglo, cuando se da la transición en el PAN entre la presidencia de Gustavo Madero Muñoz y la de Ricardo Anaya.

¿Cuál fue la causa, fin o propósito del pan en su modelo originario y en las décadas que estuvo en la oposición? Luis Medina Peña lo caracteriza como una continuación del proyecto democrático de la Revolución mexicana, del maderismo podríamos decir, y del movimiento vasconcelista que se expresó en la elección presidencial del I929:

Buena parte de la corriente moderada provino de una clase media urbana e ilustrada que defendió los ideales del movimiento vasconcelista de 1929, y cuyo énfasis fue el intento de dar contenido al propósito democrático original de la Revolución mexicana... esa clase media decidió fundar el Partido Acción Nacional (PAN) pues vio en la mecánica del partido oficial la expresión de siniestros propósitos totalitarios (Medina Peña, 2010: 158).

Lujambio y Rodríguez Doval consideran que en la fundación del PAN en 1939 coincidieron una idea, un liderazgo y una coyuntura. El liderazgo fue el de Manuel Gómez Morin; la coyuntura, el fin del sexenio cardenista. Lo que aquí nos interesa 
es la idea: claramente la de fundar un partido, que Gómez Morin tenía clara por lo menos desde 1929. De hecho, él así lo confirmó durante la fundación del partido, en 1939, al expresar: "Acción Nacional nació en I929" (Lujambio y Rodríguez Doval, 2009: 48). El antecedente más remoto es el movimiento maderista de 1909. El interés del partido fundado en 1939 puede verse como "dar contenido al propósito democrático original de la Revolución mexicana".

Si fundar un partido político era una idea planteada por Gómez Morin en 1929, ¿para qué se quería ese partido?, ¿`cuál era su fin? La respuesta podemos encontrarla en los documentos fundacionales del PAN. El lenguaje de la época es distinto al actual. Pero el fundador del pan tiene en su discurso inaugural (y en otros documentos, desde su correspondencia hasta las propuestas para la fundación de la organización y diversos discursos) una clara dicotomía: la nación versus el régimen. Así termina el texto con el que responde el discurso de Cárdenas en febrero de 1940 (Gómez Morin en Nuncio 1986: 364-365). Así lo plantea en su discurso inaugural de la Asamblea constituyente del pan en septiembre de 1939.

Ahí plantea que en México "la vida pública ha sido tan frecuentemente una mera explotación del poder, una simple sucesión de luchas y traiciones entre los profesionales de esa explotación" (PAN, 2009: II3), que el grupo que se ha adueñado del gobierno"se preocupa exclusivamente por la retención del poder mediante alianzas o complacencias exteriores disfrazadas de radicalismo" (p. II 4 ), lo que ha generado confusión política y desdén del interés nacional.

Frente a esta situación de una clase política concentrada en sus propios intereses, frente a la política confusa y contradictoria que esta situación generaba, se planteó la necesidad de dar a la nación estructura y canales de acción. No es casual el nombre de Acción Nacional: se pretendía darle a la nación posibilidades de actuar frente a un régimen que le había dado la espalda.

El lenguaje actual es muy distinto al de finales los años treinta del siglo pasado. Entonces la palabra democracia se usaba poco. $Y$ en lengua española transparencia, rendición de cuentas, balances y contrapesos eran inexistentes, o al menos inusuales. La palabra corrupción se utilizó poco en la fundación del pan. Pero la idea de un grupo político que controla el gobierno y que toma decisiones al margen o en contra de los intereses de la nación tiene que ver con todos estos términos, hoy comunes en el lenguaje de la política.

Una demostración de lo anterior es la preocupación que mostró el PAN, si no en el momento de su fundación en septiembre de 1939, sí pocos años después. En un documento dirigido a Manuel Ávila Camacho, entonces presidente de la República, fechado en octubre de 1942, el PAN planteaba la necesidad de una reforma electoral 
con argumentos y propuestas concretas que se seguirían planteando hasta los años noventa del siglo $\mathrm{xx}$ (PAN, 1942).

La idea originaria del PAN era crear un partido para estructurar a la nación y así permitirle actuar para el Estado y que sus gobiernos se condujeran en función del interés nacional, no de los intereses particulares de los políticos en el poder. Esa idea se mantuvo a lo largo de la historia panista: es la "causa" que le da alma al PAN. Es lo que explica su énfasis en la lucha electoral, en el intento de tener elecciones libres y competidas: eran un medio para vincular a la nación con la clase política, una forma de alcanzar la "auténtica representación".

Por todo lo anterior es importante el hecho de que los gobiernos panistas, en particular los dos que ocuparon la Presidencia de la República entre 2000 y 20I2, hayan hecho muy poco por acabar con la corrupción, por instaurar un entramado institucional de transparencia y rendición de cuentas que acerque la clase política a la nación. Por eso el que diversos dirigentes panistas, como exgobernadores o exdiputados, hayan sido acusados de actos graves de corrupción puede considerarse una situación de crisis para este partido.

Esta crítica ha sido planteada desde la academia (véase en Cansino y Molina Carrillo [2016] los capítulos de Cansino y Arredondo Fitz y Reveles Vázquez, y en particular el de Crespo). Los propios panistas lo han señalado en diagnósticos y documentos internos (Reynoso 2014: 27-30). La incapacidad para resolver o disminuir el problema de la corrupción, evitar el uso privado de los bienes públicos, ha sido una falla central de los gobiernos panistas y del propio partido, lo que se agrava con las acusaciones de corrupción a políticos panistas.

El pan, de acuerdo con la teoría de Michels, avanzó a la sustitución de sus fines: ya no la causa inicial, sino el mantenimiento del partido que responde a numerosos intereses particulares de sus dirigentes e integrantes. La cuestión es si se trata simplemente de una sustitución, como planteó originalmente Michels, o si es más bien una articulación; si la organización, para sobrevivir, necesita no solo recursos materiales, incentivos selectivos (desde el presupuesto público que recibe hasta los cargos públicos accesibles desde el partido), sino también incentivos colectivos, propósitos o fines que vayan más allá de los intereses de sus integrantes. El interés nacional, por ejemplo.

Después de la derrota en la elección presidencial de 2012, y con el deterioro de su imagen pública, el pan se vio obligado a un cambio. Parte de este cambio es el intento de una nueva narrativa, centrada en el combate a la corrupción. Es lo que se pretende analizar en este artículo, centrado en la coyuntura de cambio de su dirigente nacional en 2015. 


\section{El enfrentamiento Calderón-Molinar y la reconfiguración de las redes}

2015 inició para el PAN con problemas internos. El 2I de enero se publicó una entrevista en la que el expresidente Felipe Calderón criticaba fuertemente a la dirigencia del partido y mencionaba la posibilidad de dejarlo y fundar uno distinto "así sea

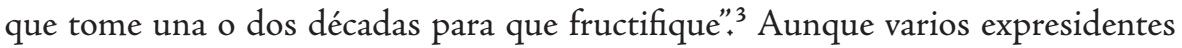
nacionales del PAN han salido de esta organización política y tratado de fundar otra, ${ }^{4}$ Calderón sería el primer expresidente de la República que lo intentaría. Su declaración tuvo repercusiones importantes en los medios y al interior de su partido.

$\mathrm{El}$ antecedente inmediato fue que su esposa, Margarita Zavala, no había podido obtener la candidatura a una diputación plurinominal. Ella es conocida sobre todo por ser la esposa de Calderón, pero tiene una trayectoria y presencia propias dentro de su partido y en la opinión pública. Desde 1993 ha sido consejera nacional del PAN, y ha sido diputada en la Asamblea Legislativa del Distrito Federal (1994-I997) y diputada federal (2003-2006). Su marginación de las listas fue vista como una exclusión deliberada por parte de Gustavo Madero, quien colocó en los mejores lugares a panistas cercanos a él. Zavala cuestionó fuertemente a Madero por haberla excluido y anunció que participaría en la elección interna para ser presidenta de su partido en el segundo semestre del año (Milenio digital, 2015).

La declaración de Calderón dio lugar a que Juan Molinar, entonces presidente de la Fundación Preciado Hernández, político muy cercano a Madero y excolaborador de Calderón, primero como director del Instituto Mexicano del Seguro Social y luego como titular de la Secretaría de Comunicaciones y Transportes, publicara una carta criticando al expresidente (Molinar, 2015a).

El título de la carta indicaba claramente que era una defensa del entonces presidente del partido, Madero, y una crítica a Calderón. Acusó a este de actuar en función de una frase supuestamente suya: "el pan es mi casa... y en mi casa mando yo". Molinar señaló en su carta que Calderón, siendo presidente de la República, impuso a dos presidentes en el PAN y que no supo tolerar que sus candidatos perdieran la

<http://www.elfinanciero.com.mx/nacional/entrevista-calderon.html> [consulta: I2/ III/20I5.

4 El más reciente, Manuel Espino (presidente del PAN de 2005 a 2007), intentó fundar un partido político. Ahora es diputado federal por Movimiento Ciudadano. En el siglo pasado Pablo Emilio Madero (presidente del pan de 1984 a 1987) y Efraín González Morfín (1975) también trataron de crear una organización política después de haber renunciado a su partido. 
candidatura a la Presidencia para 2012 (Ernesto Cordero), a la presidencia del partido en dos ocasiones (Roberto Gil en 2010 y Ernesto Cordero en 20I4). No toleró su cuarta derrota, la de su esposa Margarita Zavala, para obtener una candidatura (que según la carta de Molinar perdió en una elección interna frente a Cecilia Romero). Critica la personalidad de Calderón: "es un hombre de temperamento muy fuerte, y que le falta carácter para templar su temperamento", además de que su trato con las demás personas lo ha llevado al aislamiento, pues las lastima y maltrata.

Al día siguiente, 28 de febrero, desde Puerto Príncipe, Calderón respondió a Molinar, también mediante carta pública: "Querido Juan, mientes". El tono era similar: descalificaciones personales y políticas. Las segundas se refieren a que los miembros de la actual dirigencia panista "se representan a sí mismos, no a los ciudadanos". Que en el manejo del padrón interno ha habido casos que "rayan en la manipulación y el fraude", en la afiliación corporativa desde los gobiernos estatales y la exclusión de disidentes internos: "ni el PRI se había atrevido a tanto" (Calderón, 2015).

El mismo 28 de enero Molinar publicaría una segunda carta, muy conciliadora, en la que entre otras cosas considera que Calderón fue "un gran presidente. No miento, disiento", era el mensaje principal que el exsecretario daba al expresidente (Molinar, 2015b). Pero esta segunda carta tuvo poco impacto en los medios.

Este intercambio epistolar tiene varias aristas. Por un lado, continuaba el conflicto interno vivido en el PAN desde 2013, el más importante en este partido desde la salida de los foristas en 1992 (Reynoso, 2014). El tono de las cartas y el nivel de los interlocutores muestran que el problema seguía siendo crítico, o que incluso se había complicado, lo que debe haber dañado la imagen del partido: en las sociedades modernas los políticos son los encargados de resolver los problemas públicos, y si ellos se convierten en un problema están dejando de cumplir una función.

A lo largo del año la posición de los protagonistas dentro del pan (Madero y Molinar por un lado, Calderón y Zavala por el otro) cambió. Juan Molinar falleció el 2I de mayo de 2015 a causa de una enfermedad incurable. ${ }^{5}$ Su último acto público relevante fueron sus cartas a Calderón.

Madero, por su parte, parecía estar decidido a continuar su carrera política como coordinador de los diputados federales panistas. Se tenía la impresión de que su red dentro del partido continuaba dirigiéndolo, pues a finales de julio Ricardo Anaya,

5 Juan Molinar murió como consecuencia de esclerosis lateral amiotrófica, el 21 de mayo de 2015, menos de cuatro meses después de la publicación de su primera carta $<$ http:// www.excelsior.com.mx/nacional/2015/05/21/1025303>. 
que en zoro había sido parte de la fórmula de Madero como secretario general, ganó la elección interna por la presidencia nacional. Fue además presidente interino del partido cuando Madero solicitó licencia para buscar una candidatura a diputado federal (Prud'homme, 2016: 120).

La llegada de Anaya a la presidencia del PAN en agosto de 2015 parecía asegurar a Madero la coordinación de diputados para desde ahí buscar la candidatura a la Presidencia de la República en 2018. Pero sorpresivamente dicha coordinación recayó en Marko Cortés Mendoza (Notimex, 2015). El propio Madero aceptó que le habían ofrecido la coordinación, pero después "de un 'manotazo' le dijeron 'ya no vas"' (Jiménez, 2015).

Las razones no se hicieron públicas. Pero es indudable que con esa decisión se marginó a quien había dirigido al PAN en los últimos cinco años y que era ya un precandidato presidencial. ${ }^{6}$

Otro cambio en la configuración de la red que dirige el pan desde agosto de 2015 fue la inclusión de Margarita Zavala en la Comisión Permanente de su partido. En esta no fueron incluidos políticos cercanos a Madero, como Ulises Ramírez, Jorge Villalobos y Luis Alberto Villarreal, vinculados también a las acusaciones de los "moches" y a la fiesta de diputados panistas en Puerto Vallarta (Melgar, 2015).

Otra señal de cambio en la configuración interna del pan se dio durante la XVIII Asamblea Nacional Extraordinaria realizada el 2I de noviembre con el objetivo de reformar los estatutos partidarios. Asistieron Felipe Calderón y Margarita Zavala, y fueron mencionados por Ricardo Anaya en su discurso, una presencia que "generó sorpresa", según la crónica oficial de la reunión (Castro Cid, 2015: 5).

Parece claro que a lo largo del año se cambió la red que dirige al PAN. La de Madero fue desplazada por una nueva, centrada en Ricardo Anaya. En esta última parecen estar el expresidente Calderón y su esposa.

Es posible que los cambios tengan que ver con el intento de construir una nueva narrativa y una nueva legitimidad al PAN en torno al combate a la corrupción.

\section{Nueva narrativa: contra la corrupción}

Durante 50 años (1939-1989) el PAN no tuvo acceso a cargos políticos relevantes. La motivación de quienes militaban en ese partido era más de propósito que de

6 José Ureña (2015) planteó esta situación hasta un extremo: “La muerte política de Gustavo Madero". 
búsqueda de bienes materiales, ya fuera directamente en cargos públicos o por el acceso al presupuesto público. La llegada al poder cambió esta situación. Significó la posibilidad de recursos económicos para sus militantes. Atrajo a personas motivadas por ese tipo de bienes.

En los I2 años que gobernó el país (2000-2012) el PAN no solo no tuvo logros significativos en el combate a la corrupción. Hubo serias acusaciones, hacia políticos panistas, de incurrir en ese tipo de prácticas. Destacan los casos de los exgobernadores Luis Armando Reynoso (Aguascalientes 2004-2010) y Guillermo Padrés (Sonora 2009-2015). También el de Luis Alberto Villarreal, coordinador de los diputados panistas y político cercano a Gustavo Madero (Prud'homme, 2016: II8).

No solo el PAN no había disminuido significativamente la corrupción: la corrupción había llegado al PAN. El caso de Villarreal es notable por su cercanía con el entonces presidente nacional panista, Gustavo Madero. Los casos de los gobernadores panistas acusados de corrupción forman parte de una nueva cuestión de la agenda política mexicana, los autoritarismos subnacionales: gobiernos estatales que están lejos de responder a la dinámica democrática y de rendición de cuentas a la que se somete ya, con todas las limitaciones e imperfecciones que se quiera, al gobierno federal. Pero el caso de Luis Alberto Villarreal tiene que ver con el centro del partido como organización, no con el partido en el gobierno.

Originario de San Miguel Allende, Guanajuato, Villarreal tuvo una rápida y brillante carrera política: en el año 2000 , a los 25 años, fue electo diputado federal; en 2003 ganó la elección para presidente municipal en San Miguel Allende; tres años después es senador por Guanajuato (2006-2012); en 2012 nuevamente diputado federal. Ahí el entonces presidente nacional panista, Gustavo Madero, lo nombró coordinador de la fracción de su partido.

El propio Madero lo destituyó casi dos años después, el I3 de agosto de 20I4. La causa fue un escándalo mediático protagonizado por Villarreal: la renta, por parte de diputados panistas, de una casa en Puerto Vallarta, a la que invitaron bailarinas. Alguien filmó escenas de esa convivencia y las hizo públicas. El evento se realizó a finales de enero de 20I4, en torno a una reunión plenaria de diputados panistas que se realizó en aquella ciudad entre el 23 y el 27 de ese mes. Villarreal aceptó haber estado en la fiesta, invitado por una persona "ajena a la política”, y señaló que no se pagó con dinero de partido (Milenio digital, 2014).

Además de ese escándalo, que quizá fue lo que trascendió más en los medios, hubo acusaciones más serias de desvío de dinero. Una se refería a cantidades millonarias de recursos públicos que se otorgaron a una organización privada dirigida por la entonces esposa de Villarreal, Alma Lilia de la Rosa, quien recibió fondos 
para la asociación civil De Corazón por Guanajuato (Ricardo 2014). Otra, a una serie de actos conocidos como "los moches": una red de diputados encabezada por Villarreal que exigía a presidentes municipales un pago a cambio de asignaciones de presupuesto público por parte de la Cámara de Diputados (Redacción AN, 2013). El caso llegó hasta la PGR, pero Villarreal fue exonerado (Jiménez 20I5a).

En el contexto de estas acusaciones el pan fue incorporando en su discurso el combate a la corrupción, fuera y dentro del partido. En este empeño Ricardo Anaya Cortés, como secretario general de su partido (mayo-septiembre de 20I4), como presidente interino (septiembre de 2014-enero de 2015), como coordinador de los diputados federales (enero-junio de 2015) y luego como presidente nacional destacó por su discurso contra la corrupción (a partir de agosto de 2015).

Este renglón fue el primero de los seis en los que el pan centró su plataforma electoral para las elecciones de 2015. El "frente estratégico" inicial fue de "Combate total a la corrupción y fortalecimiento institucional". ${ }^{7}$ La propuesta en este tema es diversa y detallada, pero destaca el de la creación de un Sistema Nacional Anticorrupción, el reconocimiento de la corrupción al interior del propio partido, el fortalecimiento de la transparencia, la rendición de cuentas y la participación ciudadana, y la atención al problema del mal manejo de los recursos públicos en estados y municipios.

Por su alcance jurídico y político, y porque de alguna manera enmarca las demás propuestas, sobresale la de un Sistema Nacional Anticorrupción. Surge de la insatisfacción de la dirigencia panista frente a los resultados de la reforma en materia de transparencia, una de las realizadas en el Pacto por México. Dicho Pacto, acordado por los tres principales partidos políticos (PAN, PRI Y PRD), dio lugar a la que fue quizá la mayor reforma de la Constitución mexicana de 1917 a la fecha. ${ }^{8}$ Originó II modificaciones, una de ellas en materia de transparencia. El pAN no quedó satisfecho con ella, por lo que a finales de 2014 propuso, junto con diversos organismos de la sociedad civil, una nueva enmienda, consistente en la creación del mencionado sistema. Implicaba cambios en diversos artículos constitucionales. ${ }^{9}$

7 Los otros cinco "frentes" fueron: 2. Crecimiento justo, duradero y sostenible; 3. Justicia, derechos y convivencia nacional; 4. Bienestar y seguridad social universal; 5. Conocimiento y educación para la prosperidad, y 6 . La nación sustentable.

8 Un análisis crítico de esa reforma puede verse en Hernández Vicencio (2016: Io). La autora considera que esa etapa (entre diciembre de 2013 y abril de 2014) fue "la de mayor productividad en el Congreso de la Unión en la historia de México".

9 Puede leerse en la Plataforma Electoral del pan 2015: "Modificar y generar la legislación necesaria para la creación e implementación por completo del Sistema Nacional 
Importante también es el reconocimiento de la corrupción al interior del partido, y el compromiso de combatirla:

Deploramos que como en toda organización humana, en nuestro partido ha habido personas que incurrieron en faltas que ofendieron a los mexicanos. Con entereza hacemos frente a esta situación y reiteramos nuestro compromiso histórico de luchar frontalmente contra la corrupción (PAN, 2015a: 17).

Esta propuesta tendría como consecuencia que en la reforma de estatutos realizada por la xviri Asamblea Extraordinaria se crearan, entre otras cosas, la Comisión Anticorrupción y la Comisión de Transparencia y Reingeniería del Padrón de Militantes. A ambas se les dio carácter estatutario. Las dos quedaron presididas por panistas de larga militancia: Luis Felipe Bravo Mena la primera y Ernesto Ruffo Appel la segunda. ${ }^{10}$

Una aproximación a la presencia que tuvo el asunto de la corrupción en el discurso panista en 2015 puede verse en el cuadro I. Ahí se presenta el número de veces que aparecen las palabras "corrupción" o "anticorrupción" en el órgano oficial del PAN en 2015. Comparadas con el año anterior y con otros dos términos importantes en el lenguaje político: "igualdad" y "corrupción".

Puede verse cómo el uso de la palabra corrupción supera notablemente al de las otras dos, y se incrementa también en forma notable de 2014 a 2015. Redondeando, en 2014 el término apareció en promedio I5 veces en La Nación: en 2015 subió a 24. En el primer año la palabra "democracia" apareció I4 veces en promedio y en 2015 baja a I2, la mitad que "corrupción" o "anticorrupción" (véase cuadro I). El término igualdad tiene una presencia mucho menor y casi no varía en ambos años.

Anticorrupción, en concordancia con la propuesta de reforma que, con el apoyo de importantes organizaciones de la sociedad civil, elaboramos y presentamos ante la Cámara de Diputados a principios de noviembre de 2014, con el fin de modificar los artículos 22, 73, 74, 76, 79, I09, I13, II 4, 166 y 122 de la Constitución, dando un estricto seguimiento a la implementación de dicho sistema y promoviendo la participación ciudadana a partir de la denuncia de los actos de corrupción de los gobiernos" (PAN, 2015: 17).

10 Ambos políticos tienen una importante trayectoria dentro del pan. Luis Felipe Bravo Mena es militante panista desde 1969 y ha sido diputado federal, senador y presidente nacional del paN de 1999 a 2005, entre otros cargos públicos. Ernesto Ruffo Appel fue el primer gobernador del PAN al ganar la elección de Baja California en I989, y en 2015 era senador. 
Desde luego que una cosa es el discurso y otra las acciones. Hasta 2015 el pan no ha pasado del primero. Una excepción podría ser la exclusión de Madero de la coordinación de diputados federales. Puede interpretarse como el intento de desplazar al grupo o a la red de panistas que dio lugar a los "moches" y otras irregularidades. Pero de cualquier manera la narrativa partidaria es importante. Es un intento de recuperar el lugar que el partido tenía como una opción política distinta a otros partidos. Es la adquisición de un compromiso que si no se cumple desgastará más la imagen de la organización.

CUAdro I. Veces que aparecen las palabras corrupción o anticorrupción en cada número de La Nación en 2014 y 2015

\begin{tabular}{|c|c|c|c|c|c|c|}
\hline \multirow[t]{2}{*}{ Mes } & \multicolumn{2}{|c|}{ Corrupción } & \multicolumn{2}{|c|}{ Igualdad } & \multicolumn{2}{|c|}{ Democracia } \\
\hline & 2014 & 2015 & 2014 & 2015 & 2014 & 2015 \\
\hline Enero & 3 & 46 & 9 & I6 & 7 & 8 \\
\hline Febrero & 23 & 27 & I & 3 & II & 3 \\
\hline Marzo & 3 & 32 & 9 & 4 & 7 & 2 \\
\hline Abril & 4 & 17 & 4 & 3 & 19 & 8 \\
\hline Mayo & 2 & 37 & 5 & 3 & 15 & 14 \\
\hline Junio & 8 & 26 & 3 & o & IO & 13 \\
\hline Julio & 4 & 7 & 2 & 8 & 14 & 18 \\
\hline Agosto & 2 & 16 & 5 & 5 & 8 & 18 \\
\hline Septiembre & 12 & 32 & 5 & 4 & $2 \mathrm{I}$ & 9 \\
\hline Octubre & 9 & 20 & I & 2 & $3 I$ & 30 \\
\hline Noviembre & 74 & 8 & 3 & I & 7 & 2 \\
\hline Diciembre & $3 \mathrm{I}$ & 15 & $\mathrm{I}$ & 4 & 16 & 19 \\
\hline Suma & 175 & 283 & 48 & 53 & 166 & 144 \\
\hline Promedio mensual & 14.6 & 23.6 & 4.0 & 4.4 & 13.8 & 12.0 \\
\hline
\end{tabular}

Nota: la columna "corrupción" incluye "anticorrupción" y la columna "igualdad" incluye "desigualdad". El conteo se hizo de manera automática en el archivo PDF de la revista obtenida en internet.

En 2015, debido a que Madero solicitó licencia como presidente nacional del PAN para buscar la candidatura a diputado, hubo dos presidentes del partido: Ricardo Anaya firmó los editoriales de La Nación en enero y después a partir de agosto, seis meses en total; Gustavo Madero de febrero hasta julio, también seis meses. 


\section{Desempeño electoral}

En junio de 2015 se eligió a 500 diputados federales, nueve gobernadores y 64I diputados locales. En ambas contiendas el PAN disminuyó su número de diputados. Gobernaba dos estados y siguió gobernando dos: mantuvo Baja California Sur y perdió Sonora, pero ganó Querétaro.

El declive del pan en su número de diputados federales es constante desde 2006, tal como puede verse en este análisis. Es en parte compartido por los otros dos partidos que formaron alguna vez el tripartidismo mexicano, hoy diluido: PRI y PRD. En el caso de las elecciones de gobernador destacó el caso de Sonora, donde el gobernador panista fue objeto de fuertes críticas de corrupción. Interesa señalarlo aquí no solo por la importancia del caso en sí mismo, sino porque tiene que ver con el centro de las propuestas panistas y con la nueva narrativa que el partido ha intentado desarrollar en 2015.

El declive de los partidos en México tuvo una expresión interesante en la elección de Nuevo León. Por primera vez en el país tuvo vigencia legal la figura de candidatos independientes, es decir, no postulados por un partido político. Ahí ganó Jaime Rodríguez Calderón, expriísta que en 2015 se presentó como candidato sin partido. Hubo en este año otros dos triunfos de candidatos no postulados por partidos políticos: Manuel Clouthier en la elección de diputados federales en Sinaloa y Pedro Kumamoto como diputado local en Jalisco.

\section{Diputados federales}

Si consideramos que el actual sistema de partidos empieza con la LVII legislatura, en 1997, dado que fue la primera elección federal organizada por una autoridad electoral no presidida por el secretario de Gobernación y a partir de la cual ningún partido ha tenido mayoría absoluta, la de 2015 ha sido la peor elección de diputados para el PAN. Sólo obtuvo I08 curules, 21.6\% del total. Su número más bajo había sido de I22 (24.4\%), en la remota elección de 1997 (véase cuadro 2).

Quedó I9 puntos por debajo del partido con más diputados, el PRI, una distancia muy similar a la que ha habido entre estos dos partidos en las últimas tres legislaturas. Por tercera vez desde 2009, el PAN pierde representantes en una elección de diputados federales. Comparte esta tendencia, en términos generales, con el PRI y el PRD. Del tripartidismo vigente en I997, el sistema de partidos, expresado en 
la Cámara de Diputados federales, ha tendido a un multipartidismo (Reynoso y Montero), como puede verse en el cuadro 3.

Cuadro 2. El Partido Acción Nacional en la Cámara de Diputados Federal (1997-2015)

\begin{tabular}{|c|c|c|c|c|c|c|c|}
\hline Año & 1997 & 2000 & 2003 & 2006 & 2009 & 2012 & 2015 \\
\hline Legislatura & LVII & LVIII & LIX & LX & LXI & LXII & LXIII \\
\hline PAN & $\mathrm{I} 22$ & 207 & $15 \mathrm{I}$ & 206 & 142 & $\mathrm{II} 3$ & IIO \\
\hline$\%$ & 24.4 & $41+2$ & $30+2$ & $41+2$ & 28.4 & 23 & $21+2$ \\
\hline PRI & 239 & $2 \mathrm{II}$ & 222 & 105 & 242 & 214 & 207 \\
\hline$\%$ & 47.8 & 42.2 & 44.4 & 21 & 48.4 & 43 & 41.4 \\
\hline PRD & 125 & $5 \mathrm{I}$ & 95 & 126 & 62 & 99 & 60 \\
\hline$\%$ & 25 & I0 & 19 & $25+2$ & 12,6 & 20 & 12 \\
\hline PVEM & 8 & 16 & 17 & 19 & 22 & 27 & 42 \\
\hline$\%$ & I.6 & $3+2$ & $3+4$ & 3.8 & 4.4 & 5 & 8.4 \\
\hline MC & & $\mathrm{I}$ & 5 & 16 & 6 & 12 & 25 \\
\hline$\%$ & & 0.2 & $\mathbf{I}$ & $3+2$ & $\mathbf{I}+2$ & 2 & 5 \\
\hline PT & 6 & 8 & 6 & 14 & 14 & $\mathrm{II}$ & 6 \\
\hline$\%$ & $\mathbf{I}+2$ & $\mathrm{I}+6$ & $1+2$ & 2.8 & 2.8 & 2 & $\mathbf{I}+2$ \\
\hline PANAL & & & & 9 & 8 & IO & II \\
\hline$\%$ & & & & $\mathrm{I} .8$ & I.6 & 2 & $2+20 \%$ \\
\hline MORENA & & & & & & 12 & 35 \\
\hline$\%$ & & & & & & 3 & $7 \%$ \\
\hline PES & & & & & & & 8 \\
\hline$\%$ & & & & & & & I.6\% \\
\hline Independientes & & & & & 3 & 2 & $\mathrm{I}$ \\
\hline$\%$ & & & & & $0.6 \%$ & $4 \%$ & $0.2 \%$ \\
\hline Sin partido & & & & & & & I \\
\hline$\%$ & & & & & & & $0.2 \%$ \\
\hline Otros & & 5 & & 5 & & & \\
\hline$\%$ & & $\mathrm{I}$ & & I & & & \\
\hline NP & & & & & & 2.26 & $2.3 \mathrm{I}$ \\
\hline Total & 500 & 500 & 496 & 500 & 500 & 500 & 500 \\
\hline
\end{tabular}

Fuente: tomado de Reynoso y Montero, 2015. 
Como puede verse en el cuadro, al igual que el PRI y el PRD, el PAN presenta una tendencia a perder presencia en la Cámara de Diputados. Los datos muestran el desgaste de estos partidos. En el caso del PAN, indican que el problema va más allá de la derrota en la elección presidencial de 20I2. No se trata de un declive coyuntural, sino de una tendencia. Los conflictos internos, las continuas evaluaciones, el intento de una nueva narrativa y de propuestas contra la corrupción son parte de este proceso. Hasta 2015 los intentos panistas por revertirlo no habían tenido éxito, si consideramos los datos de la composición de la Cámara de Diputados federal.

CuAdro 3. Diputados federales de los tres principales partidos (PRI, PAN Y PRD)

\begin{tabular}{rccccccc}
\hline Año & 1997 & 2000 & 2003 & 2006 & 2009 & 2012 & 2015 \\
\hline \multirow{2}{*}{ Suma } & 486 & 469 & 468 & 437 & 446 & 426 & 366 \\
\cline { 2 - 8 } & $97.2 \%$ & $93.8 \%$ & $93.6 \%$ & $87.4 \%$ & $89.2 \%$ & $85.2 \%$ & $73.4 \%$ \\
\hline
\end{tabular}

Fuente: tomado de Reynoso y Montero, 2015.

\section{Gobernadores}

En 2015 hubo elecciones para gobernador en nueve estados. El PAN gobernaba únicamente en dos de ellos, Baja California Sur y Sonora. Mantuvo el primero y perdió el segundo. El caso de Sonora es importante por la relación que tiene con el intento del PAN de una nueva narrativa centrada en el combate a la corrupción. Aunque el partido tiene presencia en el estado desde hace varias décadas (ganó el ayuntamiento de la capital por primera vez en 1967), tuvo su primer triunfo en la elección de gobernador en 2009. Guillermo Padrés Elías resultó ser el primer panista en ganar la elección de gobernador en Sonora.

Hacia 2014 había varios señalamientos de manejos irregulares del presupuesto público, pero hubo un hecho que no se presta a interpretación: la construcción de una presa de grandes dimensiones en un rancho propiedad del gobernador Padrés, sin contar con ninguno de los permisos respectivos. El caso dio lugar a un escándalo nacional, pues además de la falta de legalidad en la construcción de la presa y en el origen de los recursos utilizados, dañó el suministro de agua de poblaciones vecinas (Larios, 2014).

La presa despareció sorpresivamente, supuestamente por los efectos del ciclón Odile. Pero diputados prístas señalaron que el propio gobernador la había man- 
dado destruir para impedir las investigaciones ya en proceso (Animal Político, 2014). El caso de Padrés es uno de los muchos a los que la Plataforma Electoral del pan pudo haberse referido cuando reconocía la corrupción al interior del pan y ofrecía combatir ese problema. ${ }^{11}$

De los siete estados en los que el PAN era oposición ganó solo Querétaro. En Colima estuvo cerca, pero fue derrotado por el PRI en una elección extraordinaria.

Estos resultados podrían verse como una expresión de la "normalidad electoral": los partidos políticos a veces ganan las elecciones, a veces las pierden, dependiendo de las múltiples variables de cada circunstancia y coyuntura. Pero las acusaciones y los hechos en torno al gobierno panista de Padrés hablan de un deterioro en los gobiernos de ese partido, o de su incapacidad para controlar la corrupción de los gobernantes surgidos de sus filas.

El pan no va solo en este desgaste. Los datos ya mencionados en el declive de los tres partidos en los resultados de las elecciones de diputados y federales indican que todos han perdido presencia en el electorado. Otro indicador es el triunfo de un candidato independiente en Nuevo León, uno de los estados económicamente más importantes del país. La figura legal de candidato independiente se estrenó en 2015. Y ese mismo año Jaime Rodríguez Calderón, "el Bronco", político con trayectoria en el PRI, ganó como independiente con 48.9\% de la votación. En Nuevo León PRI y PAN se habían alternado en el gobierno. Rodríguez Calderón los desplazó, en lo que ha sido visto como un rechazo de la ciudadanía hacia estos partidos y como la búsqueda de nuevas opciones políticas.

Cuadro 4. Partidos en la gubernatura de los estados con elecciones en 2015

\begin{tabular}{lll}
\hline Estado & Anterior & Ganador \\
\hline Baja California Sur & PAN & PAN \\
\hline Campeche & PRI & PRI \\
\hline Colima & PRI & PRI \\
\hline Guerrero & PRD & PRI \\
\hline Michoacán & PRI & PRD-PT-PANAL \\
\hline Nuevo León & PRI & Independiente: Jaime Rodríguez Calderón \\
\hline Querétaro & PRI & PAN \\
\hline San Luis Potosí & PRI & PRI \\
\hline Sonora & PAN & PRI-PVEM-PANAL \\
\hline
\end{tabular}

${ }^{11}$ Véase supra "Nueva narrativa: contra la corrupción". 
De dos gubernaturas, este partido continúa con dos. Mantuvo Baja California Sur, el estado menos poblado del país; perdió Sonora y recuperó Querétaro, que había gobernado anteriormente. Cuantitativamente no hay cambios. Cualitativamente llaman la atención las acusaciones y las evidencias de corrupción contra Guillermo Padrés. El tema del combate a la corrupción es medular al programa panista y en particular al discurso de quien fuera presidente provisional y más tarde presidente nacional electo del partido, Ricardo Anaya. Poco o nada pudieron hacer los dos gobiernos presidenciales panistas (Fox 2000-2006 y Calderón 2006-2012) para combatirla. Que un gobernante panista, como es el caso del de Sonora, sea acusado precisamente de corrupción es una grieta importante en la legitimidad del partido.

\section{Diputados locales}

En quince estados se renovaron los congresos locales en 2015. Se eligieron un total de 64I diputados. El PAN tuvo aquí una pequeña disminución, pues pasó de I59 a I49, del $24.8 \%$ al $23.2 \%$. PRI Y PRD también disminuyen su número de diputados locales, en mayor número que el PAN, pues mientras este perdió IO, el PRI tuvo una merma de 29 y el PRD de 35 (ver cuadro 5).

No parece haber un patrón que relacione el desempeño electoral del PAN, o de los demás partidos, con regiones o características socioeconómicas de los estados. Las circunstancias y coyunturas locales seguramente explican los cambios. El único patrón claro es el ya señalado en los resultados de las elecciones de diputados federales y locales: los tres grandes partidos tienden a perder votos.

Cuadro 5. Número de diputados locales por partido, 20II-20I5

\begin{tabular}{|c|c|c|c|c|c|c|c|c|c|c|c|}
\hline Entidad & Año & PAN & PRI & PRD & $\mathrm{PT}$ & PVEM & MC & NA & MORENA & OTRO & TOTAL \\
\hline \multirow{2}{*}{$\begin{array}{l}\text { Baja } \\
\text { California } \\
\text { Sur }\end{array}$} & $20 I I$ & 7 & 6 & 4 & o & o & I & I & o & 2 & $2 \mathrm{I}$ \\
\hline & 2015 & 7 & 3 & I & I & o & o & o & I & 8 & $2 I$ \\
\hline \multirow{2}{*}{ Campeche } & 2012 & 9 & 20 & 2 & $\mathrm{I}$ & $\mathrm{O}$ & $\mathrm{I}$ & 2 & $\mathrm{o}$ & o & 35 \\
\hline & 2015 & II & 15 & $\mathrm{I}$ & 0 & 3 & $\mathrm{o}$ & 2 & 3 & o & 35 \\
\hline \multirow{2}{*}{ Colima } & 2012 & 7 & II & 2 & $\mathrm{I}$ & $\mathrm{I}$ & o & 3 & o & o & 25 \\
\hline & 2015 & II & 9 & 0 & I & I & 2 & I & o & o & 25 \\
\hline
\end{tabular}




\begin{tabular}{|c|c|c|c|c|c|c|c|c|c|c|c|}
\hline Entidad & Año & PAN & PRI & PRD & $\mathrm{PT}$ & PVEM & MC & NA & MORENA & OTRO & TOTAL \\
\hline \multirow{2}{*}{ Chiapas } & 2013 & 4 & 16 & 2 & I & 13 & 2 & o & 0 & 3 & $4 \mathrm{I}$ \\
\hline & 2015 & I & IO & 2 & o & 17 & o & 3 & 2 & 6 & $4 \mathrm{I}$ \\
\hline \multirow{2}{*}{$\begin{array}{l}\text { Distrito } \\
\text { Federal }\end{array}$} & 2012 & 13 & 9 & 32 & 5 & 2 & 3 & 2 & o & o & 66 \\
\hline & 2015 & IO & 7 & 19 & I & 2 & $\mathrm{I}$ & I & 22 & 3 & 66 \\
\hline \multirow{2}{*}{ Guanajuato } & 2012 & 19 & 12 & 2 & 0 & 2 & $\mathrm{O}$ & $\mathrm{I}$ & o & 0 & 36 \\
\hline & 2015 & I9 & 8 & 3 & o & 3 & I & I & I & o & 36 \\
\hline \multirow{2}{*}{ Guerrero } & 2012 & 2 & II & 25 & 2 & 2 & 3 & I & 0 & o & 46 \\
\hline & 2015 & 2 & I8 & 15 & 2 & 6 & 2 & 0 & $\mathrm{I}$ & o & 46 \\
\hline \multirow{2}{*}{$\begin{array}{l}\text { Estado de } \\
\text { México }\end{array}$} & 2012 & II & 39 & $\mathrm{I} 2$ & 2 & 4 & 2 & 5 & 0 & o & 75 \\
\hline & 2015 & II & 34 & $\mathrm{I} 2$ & 2 & 2 & 3 & 2 & 6 & 3 & 75 \\
\hline \multirow{2}{*}{ Michoacán } & 2012 & 9 & 17 & II & I & I & o & $\mathrm{I}$ & o & o & 40 \\
\hline & 2015 & 6 & 17 & 13 & I & I & $\mathrm{I}$ & o & $\mathrm{I}$ & o & 40 \\
\hline \multirow{2}{*}{ Morelos } & 2012 & 4 & 8 & 13 & 0 & 3 & 0 & o & 0 & 2 & 30 \\
\hline & 2015 & 5 & 7 & 8 & I & 2 & I & I & I & 4 & 30 \\
\hline \multirow{2}{*}{$\begin{array}{l}\text { Nuevo } \\
\text { León }\end{array}$} & 2012 & 20 & 15 & 2 & 2 & 0 & o & 3 & 0 & o & 42 \\
\hline & 2015 & 19 & 16 & 0 & I & 2 & 3 & I & 0 & 0 & 42 \\
\hline \multirow{2}{*}{ Querétaro } & 2012 & IO & IO & $\mathrm{I}$ & o & I & $\mathrm{I}$ & 2 & o & $\mathrm{o}$ & 25 \\
\hline & 2015 & I3 & 8 & I & o & I & o & I & I & 0 & 25 \\
\hline \multirow{2}{*}{$\begin{array}{l}\text { San Luis } \\
\text { Potosí }\end{array}$} & 2012 & 6 & 9 & 2 & I & 5 & I & 2 & 0 & I & 27 \\
\hline & 2015 & 7 & 8 & 4 & I & 2 & I & 2 & I & I & 27 \\
\hline \multirow{2}{*}{ Sonora } & 2012 & 14 & $\mathrm{I} 4$ & 2 & I & o & 0 & 2 & 0 & o & 33 \\
\hline & 2015 & $\mathrm{I} 2$ & 15 & $\mathrm{I}$ & 0 & 0 & 2 & 2 & $\mathrm{I}$ & 0 & 33 \\
\hline \multirow{2}{*}{ Tabasco } & 2012 & 2 & 7 & 17 & 5 & $\mathrm{I}$ & 2 & $\mathrm{I}$ & 0 & o & 35 \\
\hline & 2015 & 2 & 8 & 13 & I & 6 & I & o & 4 & o & 35 \\
\hline \multirow{2}{*}{ Yucatán } & 2012 & 8 & 14 & 2 & I & 0 & o & 0 & 0 & o & 25 \\
\hline & 2015 & 8 & I3 & $\mathrm{I}$ & o & $\mathrm{I}$ & o & $\mathrm{I}$ & $\mathrm{I}$ & o & 25 \\
\hline Total Previo & & 159 & 235 & $\mathrm{I} 33$ & 23 & 35 & $2 \mathrm{I}$ & 26 & o & 8 & 640 \\
\hline$\%$ & & 24.8 & 36.7 & 20.8 & 3.6 & 5.5 & $3 \cdot 3$ & $4+1$ & 0 & $\mathrm{I}+3$ & 100 \\
\hline Total 2015 & & 149 & 206 & 98 & 14 & 50 & 33 & 19 & 46 & 26 & $64 \mathrm{I}$ \\
\hline$\%$ & & 23.2 & 32.1 & $15+3$ & 2.2 & 7.8 & $5+1$ & 3.0 & 7.2 & $4.1 \%$ & 100 \\
\hline
\end{tabular}

Fuente: Fuente: tomado de Reynoso y Montero, 20I5. 


\section{La elección interna}

El I6 de agosto de 2015 el pan eligió a su nuevo presidente nacional. Era la segunda vez que esta elección se realizaba con toda la militancia y la primera que se hacía en el semestre siguiente a las elecciones federales, de acuerdo con los nuevos estatutos. Hubo dos candidatos: Ricardo Anaya y Javier Corral.

Anaya era justificadamente identificado con la dirigencia de Madero, por haber sido secretario del partido durante la presidencia de este último. Javier Corral es senador de la república por Chihuahua (20I2-2018) y ha sido diputado local y federal, además de candidato a gobernador en ese mismo estado.

Igual que otras campañas internas del PAN, la de 2015 fue de fuerte confrontación

y descalificaciones. El lema de Corral fue "la rebelión de las bases" y acusó a Anaya de ser el candidato de "el consorcio", un grupo que se había apoderado del pan y que lo utilizaba para su propio beneficio, que habían hecho al PAN perder su carácter de partido de oposición (PAN, 2015b).

Anaya acusó a Corral de estar más cerca del PRD que de su propio partido. Lo comparó con Andrés Manuel López Obrador por sus actitudes y equiparó el término "consorcio" con el de "mafia" que utilizó amLo para caracterizar al grupo que a su juicio le robó el triunfo en la elección presidencial de 2006 (PAN, 2015b).

El 16 de agosto se realizó la elección. Anaya obtuvo casi $82 \%$ de la votación contra $16 \%$ de Corral. ${ }^{12}$

\section{Conclusiones}

Después de encabezar el poder Ejecutivo federal por I2 años, el Partido Acción Nacional enfrentó una crisis interna y externa que puede caracterizarse como la necesidad de articular sus fines y sus incentivos. Con el acceso al poder, atrajo militantes y dirigentes no tanto interesados en la "causa" o el propósito original del partido, sino en los recursos materiales a los que puede accederse desde el ejercicio del poder político. Aunado a esto el partido en el gobierno no fue capaz de disminuir problemas que ofreció combatir, como la corrupción y la impunidad.

Ante esta situación el PAN trató de articular sus propósitos y sus incentivos: sin dejar de ser un partido que accede al poder y lo ejerce, presentar a sus integrantes

12 El dato exacto según el órgano oficial panista fue 193944 votos para Anaya (81.9I\%) y 37953 (16.03\%) para Corral (Rizo, 2015: 3). 
y a la sociedad fines relacionados con el interés público, no solo con el de la organización y sus miembros. De aquí la necesidad de una nueva narrativa centrada en el combate a la corrupción. Ricardo Anaya, primero como presidente interino del PAN y luego como presidente electo, trató de construirla. Queda por verse si logrará la legitimidad interna y externa a su organización. Es evidente que el puro discurso, si no está ligado a acciones concretas, será insuficiente.

Esta situación se relaciona con el cambio en la configuración de las redes o grupos panistas. 2015 se inició para el panismo con la continuación de los conflictos internos que marcaron al partido desde los dos años anteriores, pero al menos aparentemente concluyó con una conciliación. La exclusión de Margarita Zavala en las listas de candidatos a diputados plurinominales en enero de 2015 llevó a su esposo Felipe Calderón a declarar que posiblemente dejaría su partido para fundar otro, terminó con la integración de Zavala en la Comisión Permanente del PAN y con la presencia "sorpresiva" de ambos cónyuges en la xvir Asamblea Nacional Extraordinaria panista en noviembre.

Paralelamente a esta integración se dio la exclusión de Gustavo Madero y su grupo: el expresidente panista no fue nombrado coordinador de los diputados federales de su partido, como se esperaba, y políticos muy cercanos a él fueron excluidos de la Comisión Permanente del partido.

Este cambio debe relacionarse con la nueva narrativa del PAN centrada en el combate a la corrupción. Impulsada por Anaya, fue reiterada durante el año analizado. Explica la exclusión del grupo cercano a Madero, de cuyos integrantes algunos habían recibido críticas por el uso privado de recursos públicos.

Tanto el cambio en la dirigencia como el nuevo discurso o narrativa deben ponerse en el contexto de la disminución de triunfos electorales para el PAN, tal como se expresa en el número de sus diputados federales desde 2009 hasta esta última elección, y también en la cantidad de diputados locales. Esta disminución, común a los tres principales partidos políticos en México y que puede considerarse una tendencia de mediano plazo, fue seguramente un factor que motivó a la nueva dirigencia partidaria a centrar su discurso o narrativa en torno al combate a la corrupción.

En dicho combate, dentro y fuera del PAN, se juega seguramente el destino de este partido. $\mathrm{O}$ al menos su identidad originaria. La cuestión, obviamente, no es solo de narrativa, sino de acciones que le den sentido y legitimidad. Estas acciones son quizá el principal punto a observar en el futuro panista. 


\section{Bibliografía y fuentes}

Agencia Reforma (2014, marzo 27), "PGR indaga a Luis Alberto Villarreal", en AM León, <http://am.com.mx/leon/mexico/pgr-indaga-a-luis-alberto-villarreal-96095.html > [consulta: 07/09/2016].

Anaya Cortés, Ricardo (2015), "Editorial" La Nación, 74(2407), p. I.

Arredondo Fitz, Paulina y Francisco Reveles Vázquez (2016), “El pan, del gobierno a la oposición", en César Cansino y Germán Molina Carrillo (2016), ¿Cuándo terminó de joderse México? El legado del Partido Acción Nacional, Puebla, Instituto de Ciencias Jurídicas de Puebla/Mariel.

Bravo Mena, Luis Felipe (2014), Acción Nacional ayer y hoy. Una esencia en busca de futuro, México, Grijalbo.

Calderón, Felipe (2015), "Querido Juan, mientes", <http://eleconomista.com. $\mathrm{mx} /$ sociedad/20I5/oI/28/querido-juan-mientes-calderon-horcasitas $>$ [consulta: $24 / 10 / 2015]$

Cansino, César (2016), "La crisis de México: el legado del paN”, en ¿Cuándo terminó de joderse México? El legado del Partido Acción Nacional, Puebla, Instituto de Ciencias Jurídicas de Puebla/Mariel.

Cansino, César y Germán Molina Carrillo (2016), ¿Cuándo terminó de joderse México? El legado del Partido Acción Nacional, Puebla, Instituto de Ciencias Jurídicas de Puebla/Mariel.

Castilla, Miriam (2015), "Rechaza el PAn postular a Margarita Zavala”, en Milenio, I3 enero, <http://www.milenio,com/politica/Rechaza_PAN_postular_a_Margarita_Zavala-Margarita_Zavala_queda_fuera_de_la_ lista_O_445155525.html> [consulta: 23/10/2015].

Castro Cid, Andrés (2015),"Partido con mayor modernidad en América Latina, acción Nacional”, La Nación, 74(2407), pp. 3-5

Crespo, José Antonio (2016), “El pan y sus desencuentros”, en César Cansino y Germán Molina Carrillo (2016), ¿Cuándo terminó de joderse México? El legado del Partido Acción Nacional, Puebla, Instituto de Ciencias Jurídicas de Puebla/Mariel.

Gómez Morin, Manuel (1986), "Informe a la nación”, en Abraham Nuncio, El PAN (alternativa de poder o instrumento de la oligarquía empresarial), México, Nueva Imagen, pp. 355-365.

Hernández Rodríguez, Rogelio (2016), Historia minima del PRI, México, El Colegio de México. 
Hernández Vicencio, Tania et al. (coords.) (2016), El orden del mercado y el desorden de la nación, México, Itaca.

Jiménez, Horacio (20I5a), "PGR exonera a Villarreal por 'moches", El Universal, abril 8, en <http://archivo.eluniversal.com.mx/ciudad-metropoli/2015/pgr-exonera-a-villarreal-por-moches-I090936.html>

Jiménez, Horacio (2015b), "Madero acusa que lo vetaron para quitarle la coordinación”, El Universal, agosto 25, en <http://www.eluniversal.com. $\mathrm{mx} /$ articulo/nacion/politica/2015/08/25/madero-acusa-que-lo-vetaron-para-quitarle-la-coordinacion $>$

Larios, Felipe (2014), "Padrés construyó represa en rancho familiar, acusan. Sañalamientos de los delegados de la Conagua, Profepa y Sagarpa en Sonora", en Milenio, 9 septiembre, en <http://www.milenio.com/ estados/Guillermo_Padres_Elias-construye_represa_ilegal-gobernador_de_Sonora_O_369563076.html> [consulta: 23/II/2015].

Lujambio, Alonso y Fernando Rodríguez Doval (2009), "Estudio introductorio”, en Partido Acción Nacional, 1939. Documentos fundacionales del Partido Acción Nacional, México.

Madero, Gustavo (2014), "Comunicado de Gustavo Madero Muñoz Presidente del Comité Ejecutivo Nacional del PAN", agosto 13, en http:// web.archive.org/web/20I4I2250824I4/http://www.pan.org.mx/ blog/2014/o8/13/comunicado-de-gustavo-madero-munoz-presidente-del-comite-ejecutivo-nacional-del-pan/ [consulta: 10/or/2016].

Medina Peña, Luis (2010), Hacia el nuevo Estado. México, 1920-1994, $3^{\mathrm{a}}$ ed., México, Fondo de Cultura Económica.

Melgar, Ivone (2015), "Margarita Zavala vuelve a la cúpula panista", Excélsior, 30 agosto en <http://www.excelsior.com.mx/nacio$\mathrm{nal} / 2015 / 08 / 30 / 1042953>$ [consulta: 02/09/2015].

Milenio digital (2014), "La fiesta no se hizo con recursos del pan': Villarreal", agosto I4, en <http://www.milenio.com/politica/Luis_ Alberto_Villarreal_PAN-video_Villarreal_PAN-fiesta_PAN_Puerto_ Vallarta_o_353964650.html> [consulta: II/Io/20I5].

Milenio digital (2015), "Veo que a algunos les doy miedo: Margarita Zavala", enero 13, en <http://www.milenio.com/politica/Margarita_Zavala_ PAN-Margarita_Zavala_diputada-presidencia_PAN_Margarita_ Zavala_O_445155721.html> [consulta: 17/02/2015].

Molinar Horcasitas, Juan (2015a), Las rutas politicas de Calderón y Madero, 27 enero, en <http://www.milenio.com/politica/Molinar_Horcasi- 
tas-Felipe_Calderon-Molinar_y_Calderon_MILFIL20I50I27_oooI. pdf> [consulta: 23/10/2015].

Molinar Horcasitas, Juan (2015b), carta dirigida a Felipe Calderón, con fecha del enero 28 de 20I5, en <http://www.elfinanciero.com.mx/nacional/ no-miento-disiento-responde-horcasitas-a-calderon.html $>$ [consulta: 28/10/2015].

Notimex (2015), "pan nombra a coordinador en la Cámara de Diputados", en El economista, 23 agosto 2015, <http://eleconomista.com.mx/socie$\mathrm{dad} / 2015 / 08 / 23 /$ marko-cortes-coordinara-pan-camara-diputados $>$ [consulta: 12/or/2016].

Nuncio, Abraham (1986), El PAN (alternativa de poder o instrumento de la oligarquia empresarial), México, Nueva Imagen.

Panebianco, Angelo (1985), Modelos de partido. Organización y poder en los partidos politicos, Madrid, Alianza Universidad.

Partido Acción Nacional (2008), "La Reforma Política. Necesidad de la reforma electoral”, en Carlos Arriola, El miedo a gobernar. La verdadera historia del pan, México, Océano, pp. 254-277.

Partido Acción Nacional (2009), 1939. Documentos fundacionales del Partido Acción Nacional, México.

Partido Acción Nacional (2015a),"Plataforma electoral 2015-2018”, en La Nación, 73(2396), pp. 14-39.

Partido Acción Nacional (2015b), Debate entre candidatos a la dirigencia nacional (2015-2018) del PAN, julio 31, en <https://www.youtube.com/watch?t $=3444 \& v=S R K l e-B k y C Q>$ [consulta: 02/08/2015].

Prud'homme, Jean Francois (2016), "El Partido Acción Nacional y el Partido de la Revolución Democrática después de las elecciones de 20i2", en Arturo Alvarado (coord.), Elecciones en México: cambios, permanencias $y$ retos, México, El Colegio de México, pp. IOI-I44.

Redacción AN (2013), “¿Cómo cobran diputados afines a Villareal 'moche' a alcaldes?" en Aristegui Noticias, noviembre 26.

Redacción Animal Político (20I4),"La extraña desaparición de la presa del gobernador de Sonora" en Animal Político, septiembre, <http://www.animalpolitico.com/2014/og/la-extrana-desaparicion-de-la-presa-del-gobernador-de-sonora/> [consulta: 23/II/20I5].

Redacción Excélsior (2015), "Fallece Juan Molinar Horcasitas", 21 de mayo, $<$ http://www.excelsior.com.mx/nacional/2015/05/21/1025303> [consulta: 15/0I/2016]. 
Reynoso, Víctor (2014), "El Partido Acción Nacional en 2013: muchos cambios, mismo contexto y mismo lugar", en Gustavo López Montiel, Rosa María Mirón Lince y Francisco Reveles Vázquez (coords.) Los estados en 2013. La nueva configuración político-electoral, México, unAm/itesm/Fundación Friedrich Naumann.

Reynoso, Víctor y Juan Carlos Montero (2015), "La nueva pluralidad de los congresos locales: ¿cambios en los sistemas de partidos locales?”, ponencia presentada al XXVI Congreso de la Sociedad Mexicana de Estudios Electorales, 13-16 de octubre, Monterrey, Nuevo León.

Ricardo, Jorge y Jorge Escalante (2014), "Consienten a esposa de Villarreal” en Reforma, mayo I7, <http://www.reforma.com/aplicacioneslibre/preacceso/articulo/default.aspx? id $=243316 \&$ urlredirect $=$ http: $/ / \mathrm{www}$. reforma.com/aplicaciones/articulo/default.aspx?id=243316> [consulta: $12 / 10 / 2015]$.

Rizo, Maricarmen (2015), "Inicia proceso de renovación y regeneración azul Ricardo Anaya Cortés", La Nación, 73(2403), p. 3.

Ureña, José (2015), "La muerte política de Gustavo Madero", en 24 horas, i3 de noviembre, <http://www.24-horas.mx/telefono-rojo-la-muerte-politica-de-gustavo-madero/> [consulta: 12/or/2016].

Villareal, Luis Albero (2014), "A los medios de comunicación”, agosto I3, <https:// www.facebook.com/notes/luis-alberto-villarreal/a-los-medios-de-comuicaci\% $\mathrm{C}_{3} \% \mathrm{~B}_{3} \mathrm{n} / 846242275410426>$

Wilson, James Q. (1995), Political Organizations, Princeton, Princeton University Press.

RESUMEN CURRICULAR

Víctor Manuel Reynoso es doctor en Ciencias Sociales con especialidad en Sociología por El Colegio de México. Ha publicado los libros Elecciones a titular del Ejecutivo en los estados del centro y centro occidente de México (coordinador junto con Francisco Lizcano, 2015); Para entender el PAN (Nostra, 2014) y Rupturas en el vértice ( $2^{\mathrm{a}} \mathrm{ed}$. en prensa, UDLAP). Actualmente es profesor de tiempo completo de la Universidad de las Américas, Puebla. Ha sido profesor y ha impartido cursos en doctorados, maestrías y licenciaturas en la Benemérita Universidad Autónoma de Puebla, La Universidad Autónoma de Tlaxcala, El Colegio de Sonora, La Universidad Nacional 
Autónoma de México, Universidad Iberoamericana Golfo Centro, entre otras. Es miembro del Sistema Nacional de Investigadores del Conacyt, en el nivel I.

Citar como: Rynoso, Víctor (2016), “Dilemas organizativos e intento de una nueva narrativa: el Partido Acción Nacional en 2015”, Iztapalapa. Revista de Ciencias Sociales y Humanidades, núm. 8I, año 37, julio-diciembre de 2016, ISSN: 2007-9176; pp. 67-94. Disponible en < http://revistaiztapalapa.izt. uam.mx/index.php/izt/issue/archive > 